\title{
Composition and Stability of the Microbial Community inside the Digestive Tract of the Aquatic Crustacean Daphnia magna
}

\author{
Heike M. Freese • Bernhard Schink
}

\begin{abstract}
Small filter-feeding zooplankton organisms like the cladoceran Daphnia spp. are key members of freshwater food webs. Although several interactions between Daphnia and bacteria have been investigated, the importance of the microbial communities inside Daphnia guts has been studied only poorly so far. In the present study, we characterised the bacterial community composition inside the digestive tract of a laboratory-reared clonal culture of Daphnia magna using 16S rRNA gene libraries and terminal-restriction length polymorphism fingerprint analyses. In addition, the diversity and stability of the intestinal microbial community were investigated over time, with different food sources as well as under starvation stress and death, and were compared to the community in the cultivation water. The diversity of the Daphnia gut microbiota was low. The bacterial community consisted mainly of Betaproteobacteria (e.g. Limnohabitans sp.), few Gammaproteobacteria (e.g. Pseudomonas sp.) and Bacteroidetes that were related to facultatively anaerobic bacteria, but did not contain typical fermentative or obligately anaerobic gut bacteria. Rather, the microbiota was constantly dominated by Limnohabitans sp. which belongs to the Lhab-A1 tribe (previously called R-BT065 cluster) that is abundant in various freshwaters. Other bacterial groups varied distinctly even under constant cultivation conditions. Overall, the
\end{abstract}

Electronic supplementary material The online version of this article (doi:10.1007/s00248-011-9886-8) contains supplementary material, which is available to authorized users.

H. M. Freese $(\bowtie) \cdot$ B. Schink

Department of Biology, Microbial Ecology,

University of Konstanz,

Universitätsstraße 10 ,

78464 Konstanz, Germany

e-mail: heike.freese@uni-konstanz.de intestinal microbial community did not reflect the community in the surrounding cultivation water and clustered separately when analysed via the Additive Main Effects and Multiplicative Interaction model. In addition, the microbiota proved to be stable also when Daphnia were exposed to bacteria associated with a different food alga. After starvation, the community in the digestive tract was reduced to stable members. After death of the host animals, the community composition in the gut changed distinctly, and formerly undetected bacteria were activated. Our results suggest that the Daphnia microbiota consists mainly of an aerobic resident bacterial community which is indigenous to this habitat.

\section{Introduction}

In aquatic ecosystems, bacteria play a key role in the degradation of organic matter which is partly mineralised to phytoplankton nutrients and partly incorporated into biomass up to higher trophic levels [2, 12]. Bacteria occur in pelagic waters, in sediments, on aggregates and also associated with higher organisms [2, 19, 21, 23, 56]. Bacteria associated with aquatic organisms can be substantially more abundant than those in ambient water [19, 23] and are also present in zooplankton guts [21, 48]. Intestinal microorganisms contribute to their host's digestion and nutrition by degradation and transformation of complex biopolymers. They may produce methane and nitrous oxide as side products $[18,47,57]$, but may also improve the host's resistance to pathogens and infections $[10,18]$. Nevertheless, the composition and stability of intestinal microbial communities in small aquatic filter feeders like cladocerans of the genus Daphnia and their interaction with their host is largely unknown. 
Daphnia spp. are often the dominant zooplankton constituent in standing freshwater systems where they act as a crucial link between primary and secondary production [49]. In addition, Daphnia spp., in particular Daphnia magna, ingest bacteria from ambient waters $[28,50]$ and can, overall, shape aquatic microbial communities [9, 37]. Carcasses of Daphnia were found to be rapidly colonised by an active bacterial community [60]. However, research on the importance of bacteria inside zooplankton guts, which Tang et al. [61] discussed in their recent review, was mainly done with copepods and intact organisms, including the carapaces with numerous epibiotic bacteria [16, 52]. Grossart et al. [17], on the other hand, demonstrated in transplantation experiments that bacterial communities associated with (intact) cladocerans (Bosmina) were much more stable than communities associated with copepods; the authors interpreted this result to be due to different gut-internal conditions. Although the cladocerans were investigated before and after gut clearance, the intestinal community itself was not directly investigated. Only one recent study [48] showed that bacteria occurred near the microvilli and gut wall of Daphnia, and it was suggested that the animals maintain a permanent gut microbiota. The major bacterial constituents of the microbiota, which were detected via CARD-FISH in a homogenate of Daphnia pulex guts, were predominantly similar to the bacterioplankton of the respective habitat [48].

Our present study aimed at analysing the microbial community inside the gut of D. magna. Since the Daphnia guts are small, we did not expect that the intestinal microbial community is dominated by anaerobic microorganisms which contribute to their host's digestion by fermentation as typical of larger animals. Rather, the intestinal community should be shaped by environmental factors such as the type of food, surrounding bacteria etc. To draw conclusion on the stability of the Daphnia microbiota, we first examined whether the microbiota of D. magna clonal cultures remains stable under constant cultivation conditions. In addition, the variability of the community due to starvation stress and death of the animals or to an alternative (xenic) food source was investigated. These experiments were performed with a $D$. magna clonal culture in order to exclude variability of the microbiota due to different host genotypes which can affect microbiota compositions (as known for other animals [e.g. 34]). As well, influences by residues of incorporated bacteria from outside and seasonal effects of the environment could be minimised this way. We used a culture-independent approach combining clonal analysis and terminal-restriction fragment length polymorphism (T-RFLP) fingerprinting analysis of 16S rRNA genes to characterise the intestinal bacterial community composition of D. magna and to investigate the stability of the microbiota over time and under starvation stress, in comparison to the cultivation water.

\section{Materials and Methods}

\section{Cultivation of Daphnia and Experimental Setup}

Stock cultures of a D. magna originating from Lake Binnensee (Northern Germany; isolated by [35]) were cultured in membrane-filtered $(0.2 \mu \mathrm{m})$ and autoclaved water from Lake Constance (LCW) at $18^{\circ} \mathrm{C}$ with a saturating supply of the green alga Scenedesmus obliquus (SAG 276-3a) grown in 'Cyano' medium [29]. Before experiments were started, Daphnia were pooled for $5 \mathrm{~h}$ in LCW at $18^{\circ} \mathrm{C}$. Afterwards, they were transferred to sterile 1-1 glass beakers (ca. 20-25 animals per beaker) filled with $500 \mathrm{ml} \mathrm{LCW}$ supplemented with ca. $1 \mathrm{mg} \mathrm{C}^{-1} \mathrm{~S}$. obliquus that had been centrifuged $(3,400 \times g$ for $7 \mathrm{~min})$, washed and resuspended with LCW. After 2 days, Daphnia were refed and, after another 2 days, were transferred to a new beaker with fresh LCW and fed again. Experiments were stopped after another 3 days of incubation (Dn-normal condition). Three experiments were conducted independently (E1-E3). Additionally, the effect of starvation was investigated. Previously normally fed Daphnia were transferred to fresh LCW and incubated without food. In E1, Daphnia were starved for 3 days whereupon most animals (nine of 15) were dead. In E2, starvation was stopped after 2 days when all individuals were still alive. In E3, starvation was not investigated but the microbial community after normal incubation was analysed in 15 and 30 guts, respectively. In parallel, Daphnia were fed with a xenic cryptophycean alga, Cryptomonas sp. SAG 26.80, as an alternative, highquality food source. In another experiment, dissected guts of Daphnia which were starved for 1 day were incubated for $0,24,48$, and $72 \mathrm{~h}$ to simulate dead animals but to avoid interference of otherwise associated bacteria. For each time point, 15 guts were placed directly into $15 \mathrm{ml}$ LCW and, after the incubation, were carefully removed with forceps.

\section{Daphnia Gut Preparation and Extraction of Microbial DNA}

Before D. magna guts were dissected, organisms were washed twice with $\mathrm{LCW}$, immobilised with $50 \mathrm{mg} \mathrm{ml}^{-1}$ $\mathrm{NaHCO}_{3}$ in LCW and washed again in LCW. The guts (including the hepatopancreas) were separated from body tissue using Dumont forceps (Fig. 1) and after a short washing step were transferred to $\mathrm{PBS}$ (phosphate-buffered saline; $8 \mathrm{~g} \mathrm{l}^{-1} \mathrm{NaCl}, 0.2 \mathrm{~g} \mathrm{l}^{-1} \mathrm{KCl}, 1.44 \mathrm{~g} \mathrm{l}^{-1} \mathrm{Na}_{2} \mathrm{HPO}_{4} \cdot 12 \mathrm{H}_{2} \mathrm{O}$, $0.24 \mathrm{~g} \mathrm{l}^{-1} \mathrm{KH}_{2} \mathrm{PO}_{4}, \mathrm{pH}$ 7.6). Wash water as well as LCW did not yield any PCR or T-RFLP products (data not shown). 
Figure 1 Dissection of a gut of Daphnia magna. Animal before preparation of the gut (a) and the dissected gut including the hepatopancreas (b) are shown. Bar equals $1 \mathrm{~mm}$
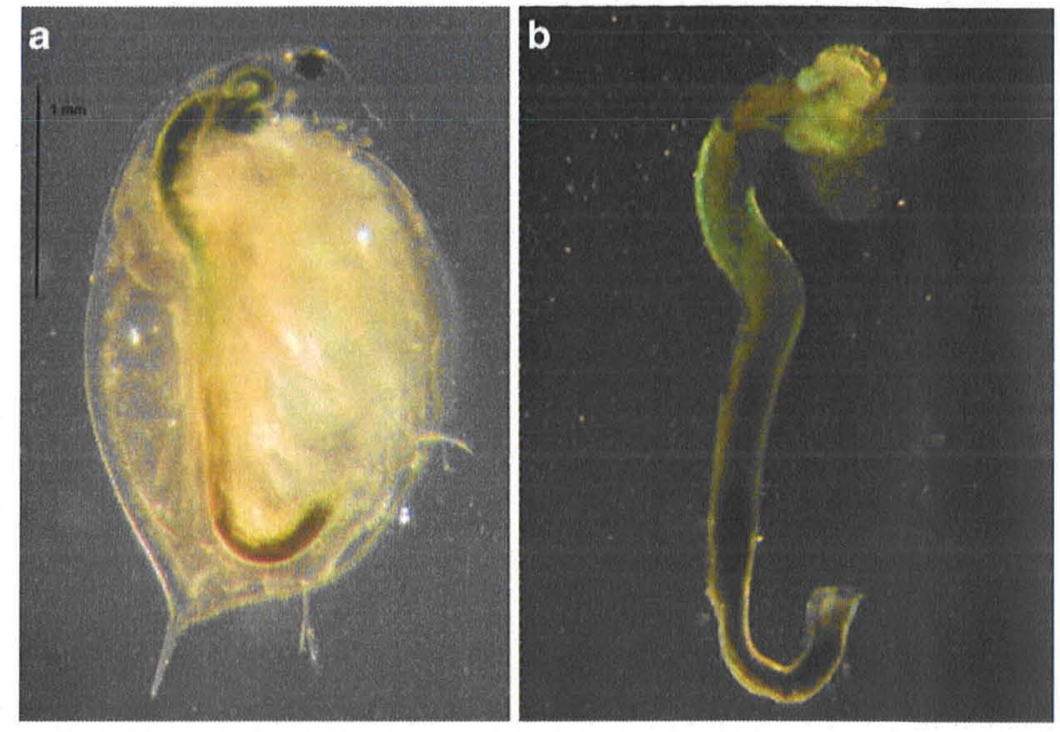

Preliminary experiments revealed that $10-15$ guts had to be pooled for successful molecular biological analysis. Dissected Daphnia guts in $1 \mathrm{ml}$ PBS were concentrated by centrifugation $(13,000 \mathrm{rpm}, 5 \mathrm{~min}$, microcentrifuge) and frozen at $-20^{\circ} \mathrm{C}$. Cultivation water $(200 \mathrm{ml})$ was filtered ( $5 \mu \mathrm{m}$, polyamide gauze; Franz Eckert GmbH, Germany) to exclude molted carapaces. Afterwards, bacteria were concentrated $(12,900 \times \mathrm{g}, 10 \mathrm{~min})$, washed with PBS and frozen at $-20^{\circ} \mathrm{C}$. Bacterial DNA was extracted from guts and water following a protocol modified after Moré et al. [43]. A small amount of zirconium beads $(0.1 \mathrm{~mm}$ diameter, sterilised at $180^{\circ} \mathrm{C}$ for at least $5 \mathrm{~h}$ ), $200 \mu \mathrm{l}$ PBS and $65 \mu \mathrm{l}$ SDS solution $(10 \%$ sodium dodecyl sulphate, $0.5 \mathrm{M}$ Tris/ $\mathrm{HCl} \mathrm{pH} 8.0 ; 0.1 \mathrm{M} \mathrm{NaCl})$ were added to each pellet. Cells and guts were disrupted by bead-beating $\left(6.5 \mathrm{~m} \mathrm{~s}^{-1}, 45 \mathrm{~s}\right.$, BIO101/Savant FastPrep ${ }^{\circledR}$ FP120) and cooled immediately on ice. Cell debris was centrifuged $(15,300 \times g, 4 \mathrm{~min})$ and the supernatant was collected. The bead-beating step was repeated with $200 \mu \mathrm{l}$ PBS at $6.5 \mathrm{~m} \mathrm{~s}^{-1}$ for $30 \mathrm{~s}$, and both supernatants were pooled. Proteins were precipitated with ammonium acetate ( 2 vol $7.5 \mathrm{M}$ to 5 vol sample, $4^{\circ} \mathrm{C}$ ), and DNA in the supernatant was precipitated with $0.7 \mathrm{vol}$ of isopropanol. After centrifugation of precipitated DNA $(20,800 \times \mathrm{g}$, $60 \mathrm{~min}, 4^{\circ} \mathrm{C}$ ) isopropanol was removed and DNA pellets were washed with $70 \%$ ethanol at $-20^{\circ} \mathrm{C}$ before DNA was dried and resuspended in $35 \mu \mathrm{l}$ buffer EB (Qiagen Elution buffer).

Other DNA extractions (e.g. with the MP Biomedicals FastDNA ${ }^{\circledR}$ SPIN Kit for Soil or Gentra Puregene Tissue Core Kit B) as well as modifications of the abovementioned method (e.g. additional incubation with mutanolysin for $30 \mathrm{~min}$ at $37^{\circ} \mathrm{C}$ ) were also tested, but less DNA was recovered (data not shown).

\section{Cloning and Phylogenetic Analysis}

Clone libraries of the intestinal bacterial community were obtained from experiment E3 (samples Dn15 and Dn30). The 16S rRNA gene PCR products from gut DNA extracts were obtained with the primer set $27 f\left(5^{\prime}\right.$-AGA GTT TGA TCC TGG CTC AG-3') and 1492r (5'-GGT TAC CTT GTT ACG ACT T-3') and for the treatment Dn30 additionally with 907r (5'-CCG TCA ATT CMT TTG AGT TT-3') [36]. The PCR products were ligated into $\mathrm{pCR}^{\circledR} 2.1$ vector according to the manufacturer's instructions (TA Cloning ${ }^{(B)}$ kit, Invitrogen). Clones with inserts were amplified by PCR using the vector-specific primers M13f (5'-TGT AAA ACG ACG GCC AGT-3') and M13r (5'-CAG GAA ACA GCT ATG ACC-3'). Ninety five clones were randomly picked and 96-well sequencing was performed at GATC Biotech AG (Konstanz, Germany) and produced sequences of 700 to $800 \mathrm{bp}$. The quality of sequences was checked with Bioedit software version 7.0.5.3 [20], and a BLAST search was performed to obtain related sequences [1]. Reference sequences were from bacterial strains which had either been published or are included in SILVA's 'The All-Species Living Tree' [62], or which were isolated in our laboratory from D. magna guts. Additionally, 16S rDNA shotgun sequences from entire Daphnia which were assigned to bacteria [52] as well as some of their closest matches were included. Sequences were aligned with the SINA Webaligner. Phylogenetic trees were calculated with MEGA4's UPGMA method (Fig. 2) and checked with the neighbour-joining method which yielded the same overall topology (data not shown) [58]. The robustness of tree topology was also tested by bootstrap analysis $(2,000$ replicates) [15]. Evolutionary distances were computed with the Maximum Composite Likelihood method [59]. 
Nucleotide sequences of the clones obtained in this study have been deposited in GenBank (accession numbers HM561429-HM561504).

Plasmids of selected clones were extracted with the Qiaprep Spin Miniprep Kit (Qiagen) to be screened by TRFLP. These clones were used as references for the T-RFLP analysis of the bacterial community in the Daphnia gut.

\section{T-RFLP Analysis}

For T-RFLP analysis, 16S rRNA genes were amplified using the primers $27 f$ and $907 \mathrm{r}$ (see above). The forward primer 27f was 5'-end labelled with 6-carboxyfluorescein (Biomers). PCR was carried out with $50-\mu l$ reaction mixtures containing 1-2 $\mu$ l gut DNA extract or $1 \mu$ of a 1:10 dilution of cloned plasmid (including 16S rRNA gene sequence inserts), each primer at $250 \mathrm{nM}$ concentration, each deoxyribonucleoside triphosphate at 30-100 $\mu \mathrm{M}$ concentration, $5 \mu \mathrm{l} 10 \times$ ThermoPol buffer and $1 \mathrm{U}$ Taq DNA Polymerase (New England BioLabs). Negative control reaction mixtures without DNA were used for each amplified set. Cycling conditions were as follows: initial denaturation at $94^{\circ} \mathrm{C}$ for $5 \mathrm{~min}, 30$ cycles of $94^{\circ} \mathrm{C}$ for $1 \mathrm{~min}, 45^{\circ} \mathrm{C}$ for $45 \mathrm{~s}$ and $72^{\circ} \mathrm{C}$ for $1.5 \mathrm{~min}$, a single final extension cycle at $72^{\circ} \mathrm{C}$ for $20 \mathrm{~min}$ and a final soak at $4^{\circ} \mathrm{C}$. Aliquots $(5 \mu \mathrm{l})$ of $16 \mathrm{~S}$ rRNA amplicons were analysed by gel electrophoresis on $1 \%$ agarose gels and visualised after staining with ethidium bromide. All PCR products and also the negative controls were purified with the MinElute PCR purification kit (Qiagen). Always two to three parallel PCR products of the same bacterial community were pooled.

Prior to digestion, amplicon concentrations were determined photometrically. DNA [200 ng for amplicons from the environmental DNA extract (with Dn E1 $100 \mathrm{ng}$ since concentration was too low) or $50 \mathrm{ng}$ for clonal amplicons or $17 \mu \mathrm{l}$ for negative controls], $2 \mu$ incubation buffer and $0.5 \mathrm{U}$ of restriction enzyme MspI (Fermentas) were combined in a total volume of $20 \mu \mathrm{l}$ and digested for $3 \mathrm{~h}$ at $37^{\circ} \mathrm{C}$. The optimal digestion time was estimated with isolated bacterial strains as that time resulting in the highest fluorescence intensity of T-RF (terminal-restriction fragment) and in the lowest percentage of pseudo-peaks (data not shown). The restriction enzyme was inactivated by incubation at $80^{\circ} \mathrm{C}$ for $20 \mathrm{~min}$. Fluorescently labelled T-RFs were size-separated in triplicate on an ABI PRISM ${ }^{\circledR}$ 3130xl Genetic Analyzer (Applied Biosystems) using an internal size standard $(0.5 \mu \mathrm{l}$ diluted in $10 \mu \mathrm{l}$ water; GeneScan 500 ROX; Applied Biosystems) and $1 \mu \mathrm{l}$ of digested DNA. Samples were denatured at $94^{\circ} \mathrm{C}$ for 5 min, immediately cooled on ice and spun down. T-RF sizes between 50 and 500 bp with peak heights of $\geq 25$ fluorescence units were determined and analysed using GeneMapper software 4.0 (Applied Biosystems). T-RF
Figure 2 Phylogenetic tree of cloned and sequenced 16S rRNA gene fragments of Daphnia magna microbiota. Clones are prefixed with 'Dn', additionally labelled with their T-RF and highlighted. Bacterial strains which were isolated from the Daphnia gut were included, too (highlighted). Clones were compared mainly with cultured bacterial strains for which NCBI accession numbers are given behind each name. Clones were also compared with bacterial 16S rDNA shotgun sequences associated with entire Daphnia (D. magna (Dm), D. pulex (Dp1) and D. pulicaria (Dp2) [52]) which were kindly provided by D. Ebert. The tree was constructed in MEGA using the UPGMA method, while evolutionary distances were computed with the Maximum Composite Likelihood method. The bar indicates the number of nucleotide substitutions per nucleotide site. The percentages of replicate trees in which the associated taxa clustered together in the bootstrap test (2,000 replicates) are shown next to the branches

peak heights of triplicates were normalised according to Dunbar at al. [13] to the smallest DNA quantity before a mean of reproducible T-RFs was calculated. Different samples were not normalised since it cannot be guaranteed that the entire DNA was completely distributed on detected peaks. In addition, T-RFLP profiles were analysed with the Additive Main Effects and Multiplicative Interaction model (AMMI) and Interaction Principal Component Analysis (IPCA) using the T-REX program (http://trex. biohpc.org/) [7]. Relative peak height was chosen as parameter and no noise filtering was used because the filtering algorithm is not suitable for samples with a low number of T-RFs.

\section{Results}

Phylogenetic Analysis of the Daphnia Gut Microbiota

Three separate clone libraries were generated from the $16 \mathrm{~S}$ rRNA gene fragments amplified from gut DNA with Bacteria-specific primer pairs. The 77 randomly selected clones were assigned to three distinct phylogenetic groups, $\beta$-proteobacteria, $\gamma$-proteobacteria and Bacteroidetes (Fig. 2). The gut libraries were found to be dominated by Limnohabitans-related clones (73\% of all clones; Table 1). These clones of the three Dn clusters (HM561429HM561483) were related closest (99.9-98.6\%, on average $99.2 \%$ ) to Limnohabitans planktonicus, a recently described facultatively anaerobic Gram-negative bacterium, and slightly less related $(98.7 \%)$ to Limnohabitans parvus [30]. These species are representatives of the recently defined Lhab-Al tribe of the betI-A clade and betI lineage which, together with the Lhab-A2 tribe, were previously defined as the freshwater R-BT065 cluster [45]. Maximal sequence differences of Daphnia gut clones belonging to the Limnohabitans group were $5.3 \%$. Most of the remaining microbiota clones were related to Leptothrix, Ideonella and Pseudomonas spp. Four Daphnia gut clones were closely related $(99.2-96.1 \%)$ to an Acinetobacter strain 

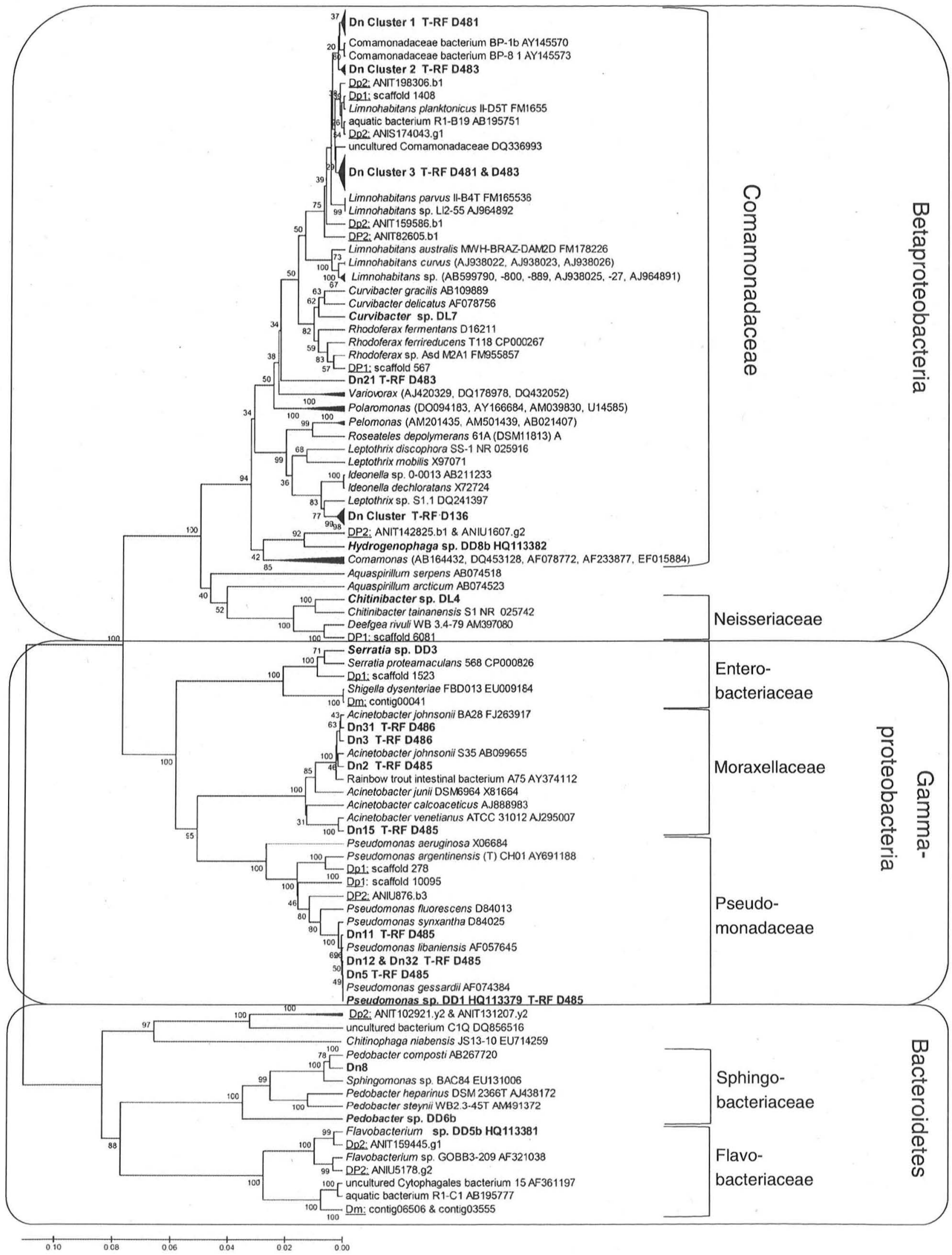
isolated from a rainbow trout intestine [26]. Some clones were also associated $(>95 \%)$ to another intestinal strain, Comamonas odontotermitis, isolated from the gut of the termite Odontotermes formosanus [6]. Only one clone was assigned to the Bacteroidetes, i.e. to Pedobacter composti [38]. In addition, a bacterial strain closely related to Pedobacter sp. and a strain affiliated to the CFB phylum were isolated from the gut of D. magna, too (Fig. 2). The reference strain $P$. compost $i$ was the only strictly aerobic strain. All other reference strains assigned to the gut clones have been described as facultatively anaerobic, but it is not always clear if these bacteria are denitrifiers or fermenters.

\section{T-RFLP Analysis of the Intestinal Bacterial Community}

Structure and diversity of the microbial community in $D$. magna guts were assessed in parallel by T-RFLP. When Daphnia were cultivated under standard conditions, the TRFLP profile of 16S rRNA gene fragments from Daphnia microbiota consisted of seven to overall 14 different reproducible T-RFs (Fig. 3), more than the number of phylogenetically different types of bacteria identified via the clone library. Double amounts of gut material used for DNA extraction did not increase the diversity and numbers of T-RFs. Three major T-RFs and two minor T-RFs could be assigned to phylogenetic groups from the gut clone library (Table 2). Overall, in silico determination of clone T-RFs revealed significant differences of 3 to $5 \mathrm{bp}$, compared to the directly assessed T-RFs. Comparison of unidentified TRFs with the T-RFLP Phylogenetic Assignment Tool resulted in a broad range of probable species hits, which even belonged to different phyla, for single T-RFs. Thus, no possible identity could be assigned to unidentified T-RFs. However, few T-RFs were also originated from bacterial strains isolated from the gut of D. magna (Table 2).

Clones affiliated to closely related Ideonella sp. and Leptothrix sp. shared the same T-RF which was constantly detected in the Daphnia gut (Fig. 3). Clones of Limnohabitans sp. differed slightly in their sequences, resulting in two separate T-RFs distinguished by two base pairs (Table 2). In the digestive tract of living Daphnia, the first Limnohabitans T-RF which also had the highest clone frequencies always produced the highest T-RF signal. The second Limnohabitans T-RF, although it was repeatedly detected in the gut, was less pronounced but accounted for a higher percentage in the cultivation water. The related taxa Pseudomonas sp. and Acinetobacter sp. originated two separate T-RFs but were not constantly detected. Although the Daphnia microbiota always generated three stable T-RFs (Limnohabitans-1, Ideonella/Leptothrix, unidentified D145) when incubated under normal conditions, the other T-RFs of the bacterial gut community changed 
Figure 3 Relative fluorescence of T-RFs from Msp1 digested bacterial 16S rRNA genes amplified from DNA extracts of Daphnia magna microbiota incubated with Scenedesmus obliquus in different experiments (E1-3; E3 30: double amount of dissected guts), with xenic Cryptomonas sp., and incubated without food in comparison to the respective cultivation water and the algal culture used for feeding. T-RFs identified via clones were named after these clones, if T-RFs were identified via bacterial isolates from the gut, the name was placed in brackets. Accurate relative fluorescence values of T-RFs can be

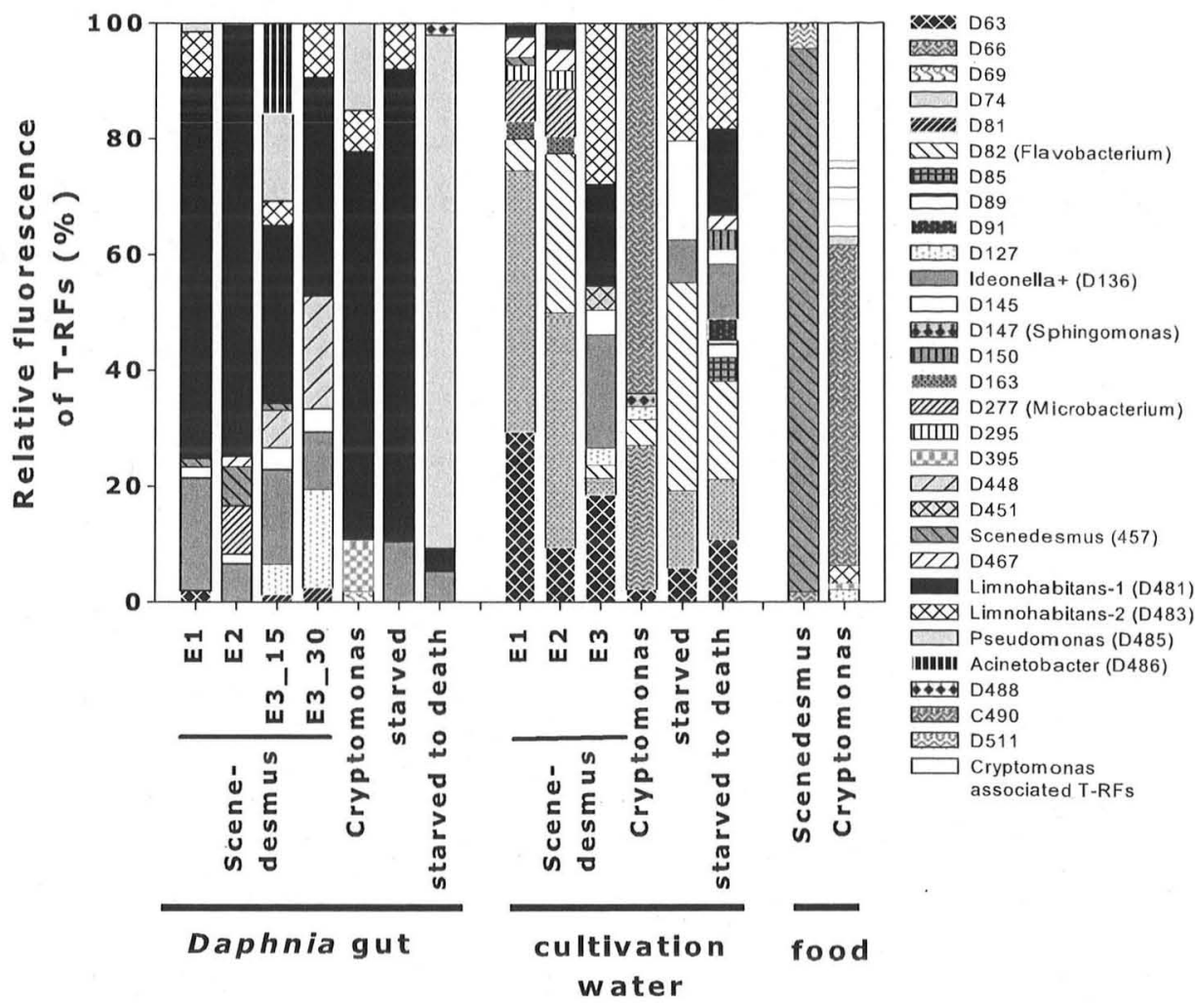

between the experiments although the conditions remained equal (Fig. 3). Some peaks were repeatedly detected while others, e.g. T-RF 277 which was also originated from the Actinobacterium Microbacterium kitamiense strain DD4 (HQ113380), were found only occasionally. Few highly variable T-RFs (e.g. Acinetobacter spp.) contributed even more than $15 \%$ to the overall composition, but most variable T-RFs occurred just with low intensities.

Table 2 Lengths (numbers of base pairs, bp) of analysed terminalrestriction fragments (T-RF, mean, minimum and maximum) and T$\mathrm{RFs}$ theoretically deduced from clone sequences and sequences from
Comparison of Intestinal and Exogenous Bacterial Community Composition

The Daphnia microbiota did not originate predominantly from bacteria associated with the food alga $S$. obliquus. Only one high T-RF peak of the concentrated algal food suspension was also detected in the microbial gut community (Fig. 3). On the other hand, the in silico restriction of the rRNA gene of a $S$. obliquus chloroplast [NCBI

phylogenetically related bacteria from NCBI (Theo T-RF) as well as the T-RF name in the community profile (Community T-RF) and the percentage of clones producing the T-RF

\begin{tabular}{|c|c|c|c|c|c|c|}
\hline Clone or isolate identity & T-RF (bp) & Min T-RF (bp) & Max T-RF (bp) & Theo T-RF (bp) & Community T-RF & $\%$ of clones \\
\hline Ideonella & 136.1 & 135.8 & 136.2 & 139 & D136 & 6 \\
\hline Leptothrix & 136.0 & & & 139 & D136 & 10 \\
\hline Limnohabitans-1 & 481.5 & 481.1 & 481.9 & 486 & D481 & 59 \\
\hline Limnohabitans-2 & 482.9 & & & 488 & & 12 \\
\hline Pseudomonas & 485.8 & 485.4 & 486.4 & 490 & D485 & 6 \\
\hline Acinetobacter & $\begin{array}{l}485.9 \\
486.3\end{array}$ & $\begin{array}{l}484.9 \\
485.9\end{array}$ & $\begin{array}{l}487.0 \\
487.0\end{array}$ & $\begin{array}{l}491(490) \\
491\end{array}$ & $\begin{array}{l}\text { D485-486 } \\
\text { D486 }\end{array}$ & 6 \\
\hline Pedobacter & - & & & 540 & & 1 \\
\hline Flavobacterium DD5b & 82.2 & 82.1 & 82.4 & & D82 & \\
\hline Sphingomonas DD7 & 147.5 & 147.4 & 147.6 & & D147 & \\
\hline Microbacterium DD4 & 277.0 & 276.6 & 277.3 & & D277 & \\
\hline
\end{tabular}


DQ396875, 8] resulted in a T-RF of 462 bp which would be in the same position as the big Scenedesmus T-RF after correction of the base pair shift. Interestingly, the bacterial community composition (T-RFs) differed distinctly between microbiota, cultivation water and algal food suspension. Although cultivation waters were supplemented with $S$. obliquus, algal T-RFs were not detected in these waters (Fig. 3). The bacterial diversity (number of T-RFs) was nearly the same in cultivation water and in Daphnia guts, whereas LCW before supplementation with algae or Daphnia did not yield any T-RFs (data not shown). Some T-RFs like D82 occurred constantly in the cultivation water, and the same was also affiliated with the CFB Flavobacterium sp. DD5b (HQ113381) while others varied highly. However, most $(60 \%)$ T-RFs from the cultivation water did not occur in the Daphnia gut even if they appeared repeatedly at highest intensities.

If a xenic Cryptomonas culture was added as the sole food source, some other different T-RFs dominated the cultivation water, and many unique T-RFs were found to be associated with the algae (Fig. 3). Nevertheless, the intestinal bacterial community was distinctly dominated by Limnohabitans T-RFs which occurred neither in the cultivation water nor associated to Cryptomonas sp., and none of the unique or cultivation water-dominating T-RFs were detected in the gut. In addition, some T-RFs were represented exclusively in the Daphnia microbiota; even major gut T-RFs were detected in cultivation waters only at low intensity, if at all.

Effect of Starvation and Death of Daphnia on the Bacterial Community Composition

Starvation of $D$. magna reduced the diversity (i.e. T-RF number) of the microbial gut community in comparison to normal incubation (Fig. 3). The most stable and dominant 'normal' bacterial gut T-RFs which were assigned to Limnohabitans sp., Ideonella sp. or Leptothrix sp. remained in the living animals through starvation for 2 days. During longer starvation, most Daphnia died but few (six of 15) survived, and the T-RF pattern shifted distinctly. The intensity of the formerly dominant Limnohabitans T-RF was considerably reduced, and the microbiota was dominated by a previously insignificant T-RF which can be attributed to Pseudomonas sp., and one further T-RF was detected for the first time at all. In contrast to cultivation water of shorter starvation experiments, the microbial community diversity in the water of longer starved Daphnia increased distinctly with several novel T-RFs (cf. Fig. 3). The novel gut-dominating Pseudomonas T-RF was not detected in the water, in neither parallel nor below the threshold (data not shown). When incubating dissected Daphnia guts over time, also the contribution of Limnohabitans-1 T-RF to the intestinal community was reduced, and the Pseudomonas T-RF was detected after $48 \mathrm{~h}$ (Fig. 4). In addition, several previously undetected T-RFs were found which dominated the bacterial community in the gut.

\section{Similarities Between Bacterial Communities}

AMMI analysis revealed that the average sample heterogeneity (i.e. beta diversity) across all T-RFLP datasets was high (10.9) and the bacterial communities differed distinctly. The differences between the sample origins accounted for $74 \%$ ( $1 \%$ noise) of the total variation among the T-RFLP patterns. Thus, bacterial communities grouped clearly according to their origin (Fig. 5). The intestinal microbiota of all living Daphnia (Scenedesmus-fed, Cryptomonas-fed and starved) clustered distinctly separate from the other bacterial communities. Within this cluster, the bacterial communities were relatively widespread indicating some variability of the microbiota. However, the microbiota of Cryptomonas-fed Daphnia was located centrally in the cluster and just $8.6 \%$ of the variability within the cluster was due to the sample origin. In contrast, bacterial communities in the cultivation water differed considerably more due to the different cultivation histories (interaction signal 75\%).

The bacterial communities in the gut of dead Daphnia also clustered distinctly separate. Especially the gut microbiota of Daphnia starved to death clustered not only separately with the first and second IPC values which explained $50 \%$ of the variance but their third IPC values covering additional $13 \%$ of variation were also clearly different $(-8.3)$ from all other samples (between -1.6 and 1.5 , data not shown). Thus, the microbiota differed from the microbiota of living Daphnia as well as from the bacterial communities in dissected guts (i.e. simulated dead animals). The bacterial community in dissected guts changed distinctly within $24 \mathrm{~h}$ but remained relatively stable afterwards (sample heterogeneity $1.6 \%$ and $17 \%$ of variability explained by time). Obviously, death of the Daphnia highly affected the intestinal microbial community resulting in the development of previously negligible gut bacteria.

\section{Discussion}

Composition and Diversity of the Daphnia Microbiota

The present study analyses for the first time the identity and stability of the intestinal microbial community of D. magna via clone libraries and T-RFLP. The bacterial community in the digestive tract of laboratory-reared $D$. magna was distinctly different from the gut microbiota of most other organisms, no matter whether terrestrial or aquatic [e.g. 14 and papers cited therein, 27, 33, 40]. Most Daphnia gut 


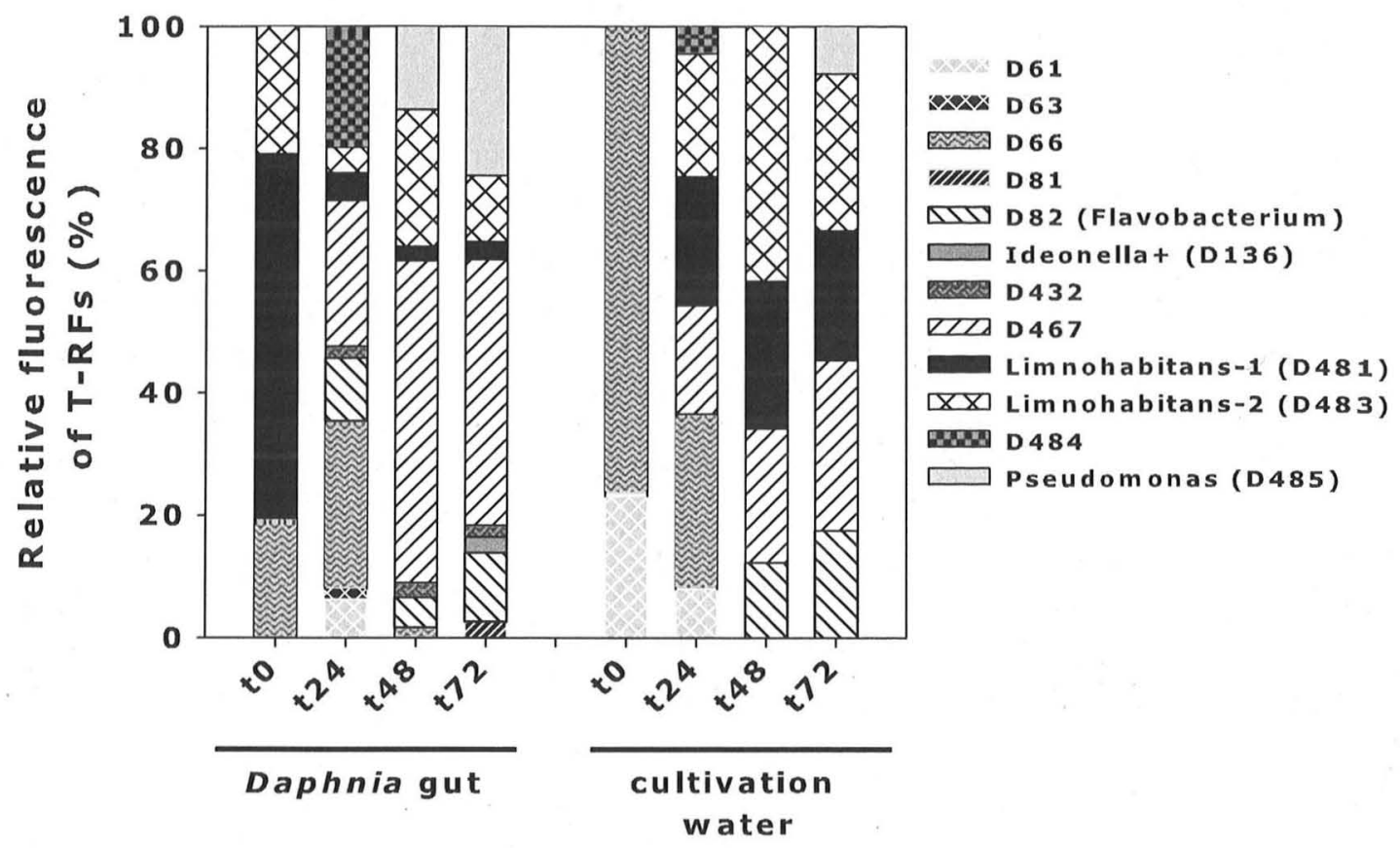

Figure 4 Relative fluorescence of T-RFs from Msp1 digested bacterial 16S rRNA genes amplified from DNA extracts of Daphnia magna microbiota and incubation water from dissected guts incubated for $0,24,48$, and $72 \mathrm{~h}$. T-RFs identified via clones were named after these clones, if T-RFs were identified via bacterial isolates from the gut, the name was placed in brackets clones were affiliated to $\beta$-proteobacteria, mainly to Limnohabitans spp. (Comamonadaceae) that are commonly found in diverse freshwater systems but so far not inside digestive tracts $[30,55]$. Several $16 \mathrm{~S}$ rDNA sequences obtained by shotgun sequencing of bacteria associated with intact Daphnia [52] were also affiliated to these bacteria. Only one intestinal strain, $C$. odontotermitis, isolated from the gut of the termite $O$. formosanus [6] was also related ( $>95 \%)$ to some of our clones. In contrast, the $\gamma$-proteobacterial clones related to Acinetobacter and Pseudomonas were commonly detected in gut systems of other aquatic animals such as fish and crabs $[26,40]$ or terrestrial crustaceans and insects $[3,24,33]$ but, as in the Daphnia gut, they were detected there only as a minor group. Clones of typical intestinal bacterial groups such as Lactobacilli, Clostridia or Enterobacteriaceae (literature see above) were not detected. One bacterial strain belonging to the Enterobacteriaceae, Serratia sp. strain DD3, was isolated from the Daphnia gut but its T-RF was never detected. In addition, only one clone represented the CFB phylum but was related to an aerobic bacterial strain [38].
Figure 5 AMMI analysis of bacterial T-RFLP profiles from the digestive tract of Daphnia magna (filled symbols)

incubated with Scenedesmus obliquus in different experiments (E1-3; E3 30: double amount of dissected guts), with xenic Cryptomonas sp., incubated without food and from dissected guts incubated up to $72 \mathrm{~h}$, in comparison to the respective cultivation water (empty symbols)

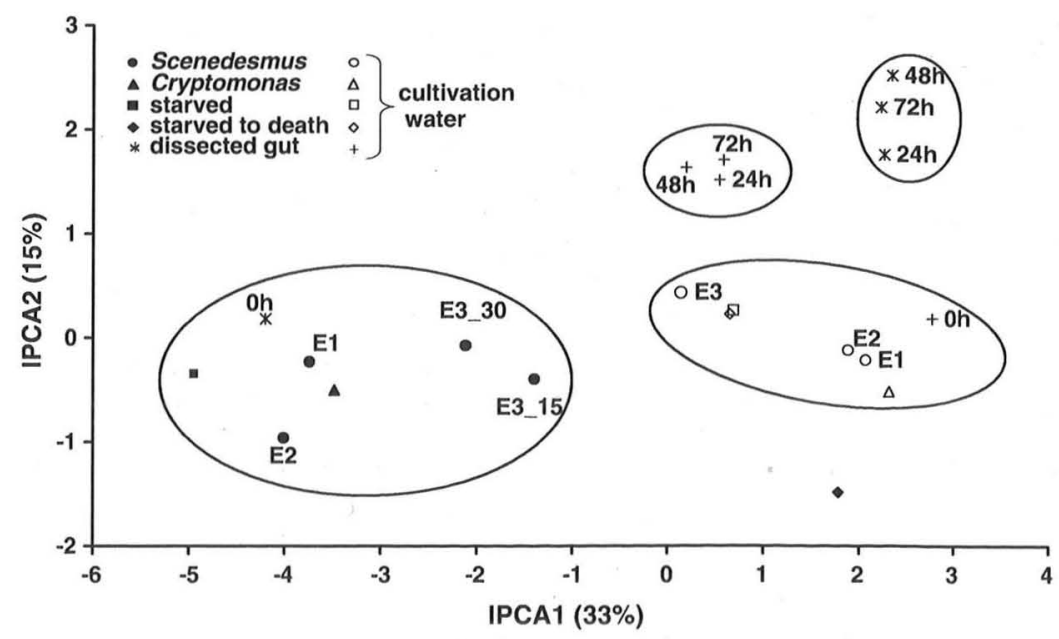


The diversity of the intestinal microbial community was less than in other terrestrial and aquatic organism (ref. see above) but appears also to be lower than that in gut homogenates of environmental $D$. pulex analysed by CARD-FISH or that of bacterial shotgun sequences from intact Daphnia [48, 52]. Although the microbiota diversities of some predatory or plant sap-sucking insects were also low, they were composed differently (mainly of Firmicutes and $\gamma$-proteobacteria) than the Daphnia microbiota [22, 39]. However, the T-RFLP profiles of the Daphnia microbiota indicated a higher diversity than the clone library analysis, and T-RFLP most likely even underestimated the species diversity of the microbial community [13, 41]. Moreover, some undetected phylogenetic groups, e.g. $\alpha$-proteobacteria and CFB, were represented by bacterial strains which we isolated from Daphnia guts. Nevertheless, laboratory maintenance of Daphnia may have artificially changed the intestinal microbial community since long-term cultivation with a homogeneous diet can reduce bacterial diversity [e. g. 31]. However, laboratory rearing of insects characterised by a less diverse microbial community had little effect on the associated bacterial community [22, 39]. In addition, Daphnia cannot survive without bacteria [51]. Thus, at least important (symbiotic) bacteria had to be maintained, although some diversity of the intestinal bacterial community may be lost. Qi et al. [52], on the other hand, demonstrated that bacteria associated with cultured Daphnia spp. were not only diverse but also remarkably similar across different Daphnia species cultivated on different continents, indicating a long-lasting stability of these associations. Some of these common bacteria, e.g. Comamonadaceae, were detected also in the gut of D. magna (this study) and even associated to the environmental cladoceran Bosmina [17]. Therefore, the intestinal bacterial community of cultured Daphnia may not be exactly identical with that of free-living animals but may likely represent the most important bacteria.

Overall, no evidence of obligately anaerobic bacteria or typical inhabitants of anoxic guts were found; rather, the Daphnia gut was dominated by clones affiliated to aerobic or facultatively anaerobic bacteria. Thus, the microbiota of Daphnia differed considerably from those of larger animals where an anaerobic microbial community contributes to their host's digestion. The small gut diameter $(<200 \mu \mathrm{m})$ and a correspondingly high surface/volume ratio as well as a fast throughput of food particles (retention time $\sim 30 \mathrm{~min}$ ) [cf. 4, 44] indicates that oxygen is available in almost the entire Daphnia gut. This was also confirmed by microelectrode measurements of oxygen profiles through the gut (unpublished data). Thus, even if some of the gut bacteria are potentially capable of fermentation, we conclude that mainly aerobic, oxygen-consuming bacteria live in the intestinal tract of Daphnia although they may produce suboxic microzones were fermentation takes place. However, this hypothesis has to be examined in more detail with physiological experiments.

\section{Dominance of Limnohabitans sp. in the Daphnia Gut}

Although $\beta$-proteobacteria are rather irrelevant in the digestive tracts of most animals, they appear to be typical intestinal bacteria in Daphnia and may even maintain a symbiotic relationship to their host. A CARD-FISH analysis of gut homogenates of environmental $D$. pulex also revealed $\beta$-proteobacteria as one major group [48]. These bacteria were also a dominant bacterial group associated with another cladocera (Bosmina) [17]. In addition, the majority of bacterial shotgun sequences from intact Daphnia were assigned to $\beta$-proteobacteria and, on average, $50 \%$ of all detected proteobacteria sequences also belonged to the family Comamonadaceae [52]. Notably, several of their few identified 16S rRNA gene sequences were affiliated to Limnohabitans sp. In the digestive tract of D. magna, these microorganisms constantly dominated the intestinal bacterial community as stable members. They dominated not only at constant conditions but also when Daphnia were starved or incubated with an alternative xenic food source in which Limnohabitans was not detected, neither associated with the algae nor in the cultivation water. Limnohabitans sp. are members of the R-BT065 cluster (tribes Lhab-A1 and -A2) typically comprising 5-30\% (up to $50 \%$ ) of the bacterioplankton of non-humic freshwater lakes $[54,55]$. These bacteria have not been detected as intestinal bacteria before, but the gut-inhabiting microorganisms were closely related to the typical planktonic bacteria $(>99 \%)$. They are known to utilise algal dissolved organic matter [46], thus the high density of algae may favour these bacteria in the Daphnia gut. Furthermore, they use acetate at a notably low rate [5], which is a typical fermentation product and one of the most important short-chain fatty acids absorbed by animal hosts [18, 47]. Members of the R-BT065 cluster are abundant and highly active (glucose or amino acid incorporation) also under anoxic conditions [5, 53] and could therefore be active in anoxic gut compartments. Although these bacteria are subject to predation by protists [54], it is not yet known if this is true also for Daphnia predation. Moreover, it was demonstrated that the proportion of metabolically active Limnohabitans cells even increased under heavy grazing pressure, and they responded rapidly to environmental changes [i.e. 25, 46, 54]. Consequently, the Daphnia gut appears to be a perfect habitat for Limnohabitans sp. of the Lhab-A1 and -A2 tribes (R-BT065 cluster). Due to the growth conditions in the gut environment, Daphnia may even serve as a reservoir where these microorganisms are enriched and constantly released into the pelagic environment. On the other hand, the stability and dominance of these 
bacteria indicate that they might have an important function for Daphnia, a subject worth to be treated in a separate study.

Variability of the Intestinal Microbial Community of Daphnia

Even though the intestinal community in Daphnia was always dominated by Limnohabitans and few other stable members, less prevalent members varied over time even when constantly fed a pure culture of algae. Some community members occurred sporadically, although at times at high intensity, while others were detected repeatedly. Peter and Sommaruga [48] detected in gut homogenates most major bacterial groups of the surrounding water, except for Actinobacteria. Thus, these variable community members could reflect bacteria from the cultivation water which were accumulated in the gut through filtration. However, in our study, the surrounding community was distinctly different from the gut microbiota. Even when Daphnia were exposed to Cryptomonas and bacteria associated with it, only few novel bacteria were detected, and the intestinal community remained highly similar. In contrast, bacteria from the cultivation water or associated with the algae were not detected inside the gut at all. Nevertheless, a change of the microbiota may be caused by uptake and stimulation of inactive or underrepresented bacteria as this was described, e.g., for the guts of earthworms [11]. However, such bacteria would need to integrate quickly into established Daphnia microbiota to compensate for the short residence time of the gut content ( 30 min; [44]). When dissected guts of $D$. magna were incubated in sterile water, the intestinal bacterial community also changed distinctly, and even novel members occurred which had not been detected previously in the guts. Thus, the variable members more likely represent less numerous bacteria that were not detected by T-RFLP [41] but were activated and thus increased their abundance over time as known, e.g., for pelagic bacteria or human gut microbiota $[18,32]$. In lake water with its more diverse bacterial communities, exogenous bacteria may have a bigger impact on the intestinal microbial community. However, Grossart et al. [17] demonstrated that bacteria associated with the cladoceran Bosmina remained highly similar also when transplanted into another lake. Thus, it can be assumed that the intestinal microbial community in Daphnia is composed, at least to a major part, of resident bacteria and is less susceptible to reflect the surrounding bacterial community. However, the importance of the surrounding bacterial community for the first inoculation of Daphnia guts and the establishment of the gut microbiota remains to be investigated.

Independent of the variability of the total community, Limnohabitans-related bacteria constantly dominated the gut, especially when Daphnia were starved. However, if Daphnia were starved to death or dissected guts were incubated (simulating dead Daphnia), Limnohabitans sp. decreased while novel bacteria appeared. One of the new dominating T-RFs probably represented bacteria related to Pseudomonas sp. Previous colonisation of the gut by these novel bacteria was possibly prevented by the established microbiota $[10,18]$, and the invading bacteria might also be digested by the host. Starvation may have reduced the fitness of the microbiota (or host) thus allowing higher densities of Pseudomonas sp. which are known to be lethal or pathogenic, e.g., for insects [3]. Feeding higher amounts of these bacteria to Daphnia resulted in a decrease of animal biomass [42].Thus, Limnohabitans sp. and other stable members may cause a colonisation resistance of the digestive tract of Daphnia which may also explain the obvious differences between the internal and the ambient microbial communities. However, whether the present intestinal community in the gut of Daphnia confers resistance against colonisation by surrounding and possibly pathogenic bacteria remains to be studied.

Acknowledgements We thank S. Wiechmann for technical assistance, A. Held for experimental assistance and E. Hespeler (chair Prof. Meyer) for help with the Genetic Analyzer for T-RFLP analysis. We are grateful to Dr D. Martin-Creuzburg and T. Basen (Limnology department) for sharing their expertise in the cultivation of Daphnia magna and Scenedesmus obliquus. We also want to thank Dr D. Ebert, Basel, who kindly provided the bacterial 16S rRNA gene shotgun sequences from intact Daphnia. This study was supported by research grants of the University of Konstanz.

\section{References}

1. Altschul SF, Gish W, Miller W, Myers EW, Lipman DJ (1990) Basic local alignment search tool. J Mol Biol 215:403-410

2. Azam F, Fenchel T, Field JG, Gray JS, Meyer-Reil LA, Thingstad F (1983) The ecological role of water-column microbes in the sea. Mar Ecol Prog Ser 10:257-263

3. Ben Ami E, Yuval B, Jurkevitch E (2010) Manipulation of the microbiota of mass-reared Mediterranean fruit flies Ceratitis capitata (Diptera: Tephritidae) improves sterile male sexual performance. ISME J 4:28-37

4. Brune A (1998) Termite guts: the world's smallest bioreactors Trends Biotechnol 16:16-21

5. Buck U, Grossart HP, Amann R, Pernthaler J (2009) Substrate incorporation patterns of bacterioplankton populations in stratified and mixed waters of a humic lake. Environ Microbiol 11:1854 1865

6. Chou JH, Sheu SY, Lin KY, Chen WM, Arun AB, Young CC (2007) Comamonas odontotermitis sp. nov., isolated from the gut of the termite Odontotermes formosanus. Int J Syst Evol Microbiol 57:887-891

7. Culman S, Bukowski R, Gauch H, Cadillo-Quiroz H, Buckley D (2009) T-REX: software for the processing and analysis of T-RFLP data. BMC Bioinformatics 10:171

8. de Cambiaire JC, Otis C, Lemieux C, Turmel M (2006) The complete chloroplast genome sequence of the chlorophycean 
green alga Scenedesmus obliquus reveals a compact gene organization and a biased distribution of genes on the two DNA strands. BMC Evol Biol 6:37

9. Degans H, Zollner E, Van der Gucht K, De Meester L, Jürgens K (2002) Rapid Daphnia-mediated changes in microbial community structure: an experimental study. FEMS Microbiol Ecol 42:137149

10. Dillon RJ, Dillon VM (2004) The gut bacteria of insects: nonpathogenic interactions. Annu Rev Entomol 49:71-92

11. Drake HL, Horn MA (2007) As the worm turns: the earthworm gut as a transient habitat for soil microbial biomes. Annu Rev Microbiol 61:169-189

12. Ducklow HW, Purdie DA, Williams PJL, Davies JM (1986) Bacterioplankton: a sink for carbon in a coastal marine plankton community. Science 232:865-867

13. Dunbar J, Ticknor LO, Kuske CR (2001) Phylogenetic specificity and reproducibility and new method for analysis of terminal restriction fragment profiles of $16 \mathrm{~S}$ rRNA genes from bacterial communities. Appl Environ Microbiol 67:190 197

14. Egert M, Wagner B, Lemke T, Brune A, Friedrich MW (2003) Microbial community structure in midgut and hindgut of the humus-feeding larva of Pachnoda ephippiata (Coleoptera: Scarabaeidae). Appl Environ Microbiol 69:6659-6668

15. Felsenstein J (1985) Confidence limits on phylogenies - an approach using the bootstrap. Evolution 39:783-791

16. Green J (1974) Parasites and epibionts of Cladocera. Trans Zool Soc Lond 32:417-515

17. Grossart HP, Dziallas C, Tang KW (2009) Bacterial diversity associated with freshwater zooplankton. Environ Microbiol Rep $1: 50-55$

18. Guarner F, Malagelada JR (2003) Gut flora in health and disease. Lancet 361:512-519

19. Haglund AL, Törnblom E, Boström B, Tranvik L (2002) Large differences in the fraction of active bacteria in plankton, sediments, and biofilm. Microb Ecol 43:232-241

20. Hall TA (1999) Bioedit: a user-friendly biological sequence alignment editor and analysis program for Windows 95/98/NT Nucleic Acids Symp Ser 41:95-98

21. Harris JM (1993) The presence, nature, and role of gut microflora in aquatic invertebrates - a synthesis. Microb Ecol 25:195-231

22. Haynes S, Darby AC, Daniell TJ, Webster G, van Veen FJF, Godfray HCJ, Prosser JI, Douglas AE (2003) Diversity of bacteria associated with natural aphid populations. Appl Environ Microbio 69:7216-7223

23. Hentschel U, Usher KM, Taylor MW (2006) Marine sponges as microbial fermenters. FEMS Microbiol. Ecol 55:167-177

24. Hongoh Y, Ohkuma M, Kudo T (2003) Molecular analysis of bacterial microbiota in the gut of the termite Reticulitermes speratus (Isoptera; Rhinotermitidae). FEMS Microbiol Ecol 44:231-242

25. Hornák K, Jezbera J, Nedoma J, Gasol JM, Šimek K (2006) Effects of resource availability and bacterivory on leucine incorporation in different groups of freshwater bacterioplankton, assessed using microautoradiography. Aquat Microb Ecol 45:277289

26. Huber I, Spanggaard B, Appel KF, Rossen L, Nielsen T, Gram L (2004) Phylogenetic analysis and in situ identification of the intestinal microbial community of rainbow trout (Oncorhynchus mykiss, Walbaum). J App Microbiol 96:117-132

27. Jiang Y, Xie CX, Yang GG, Gong XL, Chen XJ, Xu LX, Bao BL (2011) Cellulase-producing bacteria of Aeromonas are dominant and indigenous in the gut of Ctenopharyngodon idellus (Valenciennes). Aquacult Res 42:499-505

28. Jürgens K (1994) Impact of Daphnia on planktonic microbial food webs - a review. Mar Microbial Food Webs 8:295-324
29. Jüttner F, Leonhardt J, Mohren S (1983) Environmental-factors affecting the formation of mesityloxide, dimethylallylic alcohol and other volatile compounds excreted by Anabaena cylindrica. J Gen Microbiol 129:407-412

30. Kasalicky V, Jezbera J, Šimek K, Hahn MW (2010) Limnohabitans planktonicus sp. nov., and Limnohabitans parvus sp. nov., two novel planktonic Betaproteobacteria isolated from a freshwater reservoir and emended description of the genus Limnohabitans. Int J Syst Evol Microbiol 60:2710-2714

31. Kassen R, Rainey PB (2004) The ecology and genetics of microbial diversity. Annu Rev Microbiol 58:207-231

32. Kirchman DL, Dittel AI, Findlay SEG, Fischer D (2004) Changes in bacterial activity and community structure in response to dissolved organic matter in the Hudson River, New York. Aquat Microb Ecol 35:243-257

33. Kostanjšek R, Štrus J, Avguštin G (2002) Genetic diversity of bacteria associated with the hindgut of the terrestrial crustacean Porcellio scaber (Crustacea: Isopoda). FEMS Microbiol Ecol 40:171-179

34. Kovacs A, Ben Jacob N, Tayem H, Halperin E, Iraqi F, Gophna U (2011) Genotype is a stronger determinant than sex of the mouse gut microbiota. Microb Ecol 61:423-428

35. Lampert W (1991) The dynamics of Daphnia in a shallow lake. Verh Int Ver Limnol 24:795-798

36. Lane DJ (1991) 16S/23S rRNA sequencing. In: Stackebrandt E, Goodfellow M (eds) Nucleic acid techniques in bacterial systematics. Wiley, Chichester, pp 115-175

37. Langenheder S, Jürgens K (2001) Regulation of bacterial biomass and community structure by metazoan and protozoan predation. Limnol Oceanogr 46:121-134

38. Lee HG, Kim SG, Im WT, Oh HM, Lee ST (2009) Pedobacter composti sp. nov., isolated from compost. Int J Syst Evol Microbiol 59:345-349

39. Lehman R, Lundgren J, Petzke L (2009) Bacterial communities associated with the digestive tract of the predatory ground beetle, Poecilus chalcites, and their modification by laboratory rearing and antibiotic treatment. Microb Ecol 57:349-358

40. Li K, Guan W, Wei G, Liu B, Xu J, Zhao L, Zhang Y (2007) Phylogenetic analysis of intestinal bacteria in the Chinese mitten crab (Eriocheir sinensis). J Appl Microbiol 103:675 682

41. Liu WT, Marsh TL, Cheng H, Forney LJ (1997) Characterization of microbial diversity by determining terminal restriction fragment length polymorphisms of genes encoding 16S rRNA. Appl Environ Microbiol 63:4516-4522

42. Martin-Creuzburg D, Beck B, Freese HM (2011) Food quality of heterotrophic bacteria for Daphnia magna: evidence for a limitation by sterols. FEMS Microbiol Ecol. doi:10.1111/j.15746941.2011.01076.x:

43. Moré MI, Herrick JB, Silva MC, Ghiorse WC, Madsen EL (1994) Quantitative cell lysis of indigenous microorganisms and rapid extraction of microbial DNA from sediment. Appl Environ Microbiol 60:1572-1580

44. Murtaugh PA (1985) The influence of food concentration and feeding rate in the gut residence time of Daphnia. J Plankton Res 7:415-420

45. Newton RJ, Jones SE, Eiler A, McMahon KD, Bertilsson S (2011) A guide to the natural history of freshwater lake bacteria. Microbiol Mol Biol Rev 75:14-49

46. Pérez MT, Sommaruga R (2006) Differential effect of algal- and soil-derived dissolved organic matter on alpine lake bacterial community composition and activity. Limnol Oceanogr 51:25272537

47. Pester M, Brune A (2007) Hydrogen is the central free intermediate during lignocellulose degradation by termite gut symbionts. ISME J 1:551-565 
48. Peter H, Sommaruga R (2008) An evaluation of methods to study the gut bacterial community composition of freshwater zooplankton. J Plankton Res 30:997-1006

49. Peters RH, de Bernardi R (1987) Daphnia. Mem Ist Ital Idrobiol 45:1-502

50. Peterson BJ, Hobbie JE, Haney JF (1978) Daphnia grazing on natural bacteria. Limnol Oceanogr 23:1039-1044

51. Proulx D, Lésel R, de la Noüe J (1984) Growth of Daphnia magna in axenic, monoxenic and holoxenic conditions. Rev Franc Sci 1'Eau 3:83-91

52. Qi W, Nong G, Preston J, Ben Ami F, Ebert D (2009) Comparative metagenomics of Daphnia symbionts. BMC Genomics 10:172

53. Salcher MM, Pernthaler J, Zeder M, Psenner R, Posch T (2008) Spatio-temporal niche separation of planktonic Betaproteobacteria in an oligo-mesotrophic lake. Environ Microbiol 10:2074-2086

54. Šimek K, Hornák K, Jezbera J, Mašín M, Nedoma J, Gasol JM, Schauer M (2005) Influence of top-down and bottom-up manipulations on the R-BT065 subcluster of beta-proteobacteria, an abundant group in bacterioplankton of a freshwater reservoir. Appl Environ Microbiol 71:2381-2390

55. Šimek K, Kasalický V, Jezbera J, Jezberová J, Hejzlar J, Hahn MW (2010) Broad habitat range of the phylogenetically narrow RBT065 cluster, representing a core group of the betaproteobacterial genus Limnohabitans. Appl Environ Microbiol 76:631-639
56. Simon M, Grossart HP, Schweitzer B, Ploug H (2002) Microbial ecology of organic aggregates in aquatic ecosystems. Aquat Microb Ecol 28:175-211

57. Stief P, Poulsen M, Nielsen LP, Brix H, Schramm A (2009) Nitrous oxide emission by aquatic macrofauna. Proc Natl Acad Sci USA 106:4296-4300

58. Tamura K, Dudley J, Nei M, Kumar S (2007) MEGA4: molecular evolutionary genetics analysis (MEGA) software version 4.0. Mol Biol Evol 24:1596-1599

59. Tamura K, Nei M, Kumar S (2004) Prospects for inferring very large phylogenies by using the neighbor-joining method. Proc Natl Acad Sci USA 101:11030-11035

60. Tang KW, Bickel SL, Dziallas C, Grossart HP (2009) Microbial activities accompanying decomposition of cladoceran and copepod carcasses under different environmental conditions. Aquat Microb Ecol 57:89-100

61. Tang KW, Turk V, Grossart HP (2010) Linkage between crustacean zooplankton and aquatic bacteria. Aquat Microb Ecol 61:261-277

62. Yarza P, Richter M, Peplies J, Euzeby J, Amann R, Schleifer KH, Ludwig W, Glöckner FO, Rosselló-Móra R (2008) The All-Species Living Tree project: a 16S rRNA-based phylogenetic tree of all sequenced type strains. Syst Appl Microbiol 31:241-250 